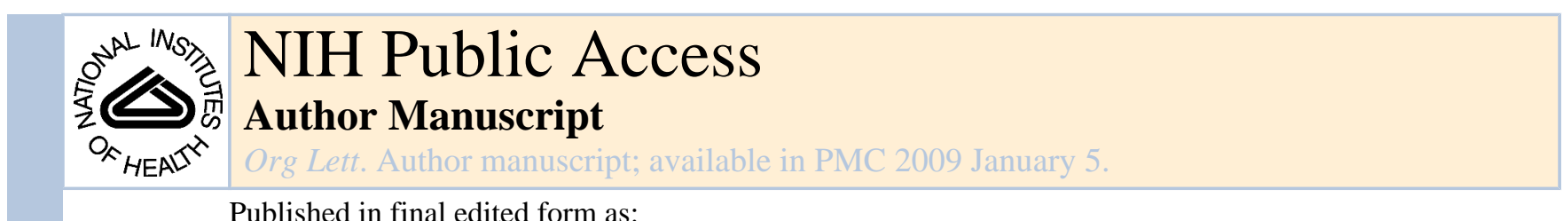

Org Lett. 2006 June 22; 8(13): 2771-2774. doi:10.1021/ol060828b.

\title{
Novel Approach to Multifunctionalized Homoallylic Alcohols via Regioselective Ring Opening of Aryl Oxiranes with 3-lodo Allenoates
}

\author{
Adiseshu Kattuboina, Parminder Kaur, Cody Timmons, and Guigen Li \\ Department of Chemistry \& Biochemistry, Texas Tech University, Lubbock, TX-79409-1061.
}

\begin{abstract}

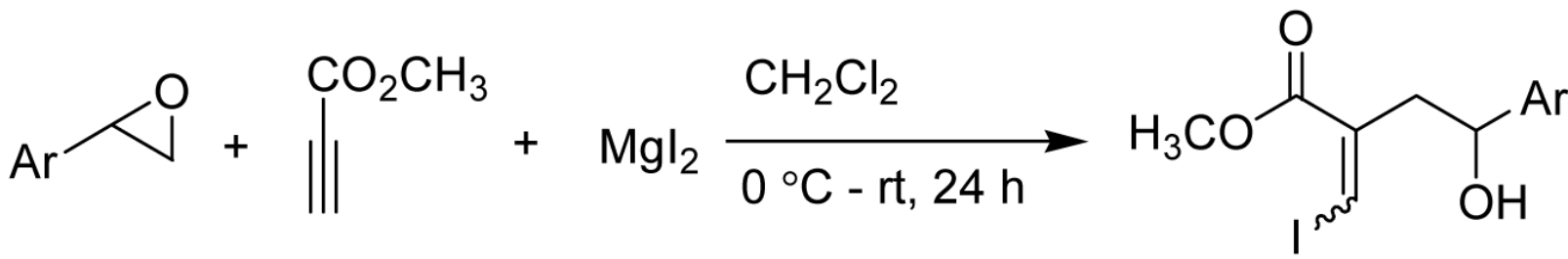

3-Iodo allenoates were generated in situ and utilized, for the first time, in the ring opening of oxiranes in a regioselective fashion. This simple one-pot three-component reaction protocol provides an easy access to highly functionalized homoallylic alcohols in good yields and moderate to very good (Z:E) selectivity. The two functional groups (ester and halogen) can be further subjected to many synthetic transformations.
\end{abstract}

yields up to $87 \%$
$(Z: E)$ selectivity up to $>20: 1$

Homoallylic alcohols are valuable building blocks for the synthesis of complex natural products and biologically active compounds. ${ }^{1-2}$ These versatile precursors can be used for a variety of important reactions such as Prins cyclization reactions, ${ }^{3}$ cycloaddition reactions with nitrile oxides, ${ }^{4}$ epoxidations,,${ }^{5,2}$ and aziridinations. ${ }^{6}$ Over the past several decades, there have been numerous methods reported for the synthesis of homoallylic alcohols. ${ }^{7}$ Most have involved either the allylation of carbonyl compounds or carbonyl-ene reactions. Obviously, the introduction of additional functionality onto these homoallylic alcohols could greatly enhance their versatility, and increase their utility for target oriented synthesis. Unfortunately, there have been very few methods for the selective synthesis of multifunctionalized homoallylic alcohols reported so far. ${ }^{8}$ Very recently, Loh et al. reported an interesting tandem allyl transfer/olefin cross metathesis reaction for the enantioselective synthesis of homoallylic alcohols having an ester group at C-4. This method gives moderate yields in the case of aliphatic aldehydes but fails with aromatic aldehydes. ${ }^{9}$

From the works of Kishi, ${ }^{10} \mathrm{Lu}^{11}$ and our group ${ }^{12}$ it is now well established that catalyst systems such as $\mathrm{TiCl}_{4} /(n \text {-Bu })_{4} \mathrm{NI}$, trimethylsilyl iodide (TMSI), $\mathrm{Et}_{2} \mathrm{AlI}$, and $\mathrm{MgI}_{2}$ can effectively transfer iodide anion to $\alpha, \beta$-acetylenic ketones/esters to give 3 -iodo allenolates/3-

guigen.li@ttu.edu.

Supporting Information Available: Experimental details and characterization data for the products. This material is available free of charge via the Internet at http://pubs.acs.org 
iodo allenoates. These 3-iodo allenoates can be reacted with electrophiles such as aldehydes and imines to afford $\beta$-iodo Morita-Baylis-Hillman (MBH) adducts and $\beta$-iodo aza-MoritaBaylis-Hillman adducts, respectively (Scheme 1). ${ }^{12}$

We envisaged that such a reaction of 3-iodo allenoates with oxiranes as electrophilic partners would result in homoallylic alcohols with ester and iodo groups on the 3 and 4-positions, respectively. We herein report our preliminary results on the reaction of 3-iodo allenoates with aryl oxiranes to give functionalized homoallylic alcohols. To the best of our knowledge, this is the first example of the synthesis of 3,4-difunctionalized homoallylic alcohols.

Initial attempts to open phenyl oxirane ring with in situ-generated 3-iodo allenoate derived from $\mathrm{Et}_{2} \mathrm{AlI}$ as a Lewis acid and also as the iodide anion source were unfruitful. No appreciable conversion was observed even after $24 \mathrm{~h}$ at room temperature. We next utilized TMSI to replace $\mathrm{Et}_{2} \mathrm{AlI}$ for the generation of the 3-iodo trimethylsilyl allenoate for the phenyl oxirane ring opening, no product was observed at all. Fortunately, when we switched to $\mathrm{MgI}_{2}$ as the Lewis acid/iodide anion source for the tadem $\alpha, \beta$-unsaturated addition/ring opening a 57\% yield of the product was obtained after stirring at $0{ }^{\circ} \mathrm{C}$ for $24 \mathrm{~h}$. The yield was later improved to $69 \%$ when the methyl propiolate/ $\mathrm{MgI}_{2}$ combination was used in excess.

Based on previous ring openings, it was anticipated that the 3-iodo allenoate could attack phenyl oxirane both at its benzylic carbon (path a, Scheme 2) and at its terminal carbon (path b, Scheme 2) leading to the regioisomers 1 and $\mathbf{2}$. It was also found that the chemical yields and regioselectivity of oxirane ring opening depends on the reaction media, the solvent, and the temperature. The reaction was performed at both $0{ }^{\circ} \mathrm{C}$ and room temperature in various solvents. The results are summarized in Table 1.

Interestingly, in the present study, ${ }^{1} \mathrm{H}$ NMR analysis of the crude product showed that oxirane ring opening occurred predominantly at the less hindered terminal carbon (path b) of phenyl oxirane leading to the formation of 3,4-disubstituted homoallylic alcohol 2, although the reaction was performed under Lewis acid conditions. The resulting $Z, E$ isomers of $\mathbf{2}$ could be easily separated by $\mathrm{SiO}_{2}$ flash column chromatography.

The (Z:E) stereochemistry was unambigiously determined by NOESY spectral analysis. The 2-D NOESY spectrum ( $500 \mathrm{MHz} ; \mathrm{CDCl}_{3}$ ) of the major isomer of $\mathbf{2}$ showed strong correlations between vinylic proton and methylene protons on $\mathrm{C}-2$, and with the methine proton on $\mathrm{C}-1$, whereas in the 2-D NOESY spectrum of minor isomer, no correlations between vinylic proton and other protons were observed (Figure 1).

As revealed in Table 1, the yield improved significantly when the temperature was raised to rt from $0{ }^{\circ} \mathrm{C}$ without effecting the (Z:E) selectivity (entries 1 and 2, Table 1). Methylene chloride was found to be the best solvent for this reaction, giving the highest yields, with only a slight decrease in (Z:E) selectivity (entries 2 and 4 ).

The optimal reaction conditions are as follows. In a dry reaction vial filled with $\mathrm{N}_{2}$, is added $1.0 \mathrm{mmol}$ of $\mathrm{MgI}_{2}$ and $3.0 \mathrm{~mL}$ of dry methylene chloride. The vial is cooled to $0{ }^{\circ} \mathrm{C}$ and 1.0 mmol of methyl propiolate is added. After stirring for $2 \mathrm{~h}$ at this temperature, $0.75 \mathrm{mmol}$ of aryl oxirane present in $1.0 \mathrm{~mL}$ of methylene chloride is added to the resulting mixture. Stirring is continued at $0{ }^{\circ} \mathrm{C}$ for $12 \mathrm{~h}$ and then the temperature is raised to room temperature and stirred for another $12 \mathrm{~h}$.

Ten different aryl oxiranes ${ }^{13}$ were subjected to the aforementioned ring-opening under the above optimized reaction conditions. The results are summarized in Table 2. Both electron withdrawing groups (entries 2, 3 and 6) and electron donating groups (entries 4, 5, 7, 8 and 10) on the aromatic system give good results in this reaction, although the yields are slightly higher 
with those substrates where the oxirane is attached to electron withdrawing groups. As can be seen from Table 2, the (Z:E) selectivity was found to vary significantly with the position of substituents on the phenyl ring (compare entries 3, 4 and 5 with 6,7 and 8).

When (2-chloro)phenyl substituent was employed (entry 6), the selectivity has increased to 10:1 (compare with entry 3). The maximum (Z:E) selectivity of $>20: 1$ was achieved with (2methoxy)phenyl substituent (entry 7). However, the yields were slightly lower with ortho substituted aryl oxiranes (entries 6,7 and 8). Meta substitution on the phenyl ring did not have an obvious affect on (Z:E) selectivity in the product (entry 10).

Another noteworthy point is that the reaction gave satisfactory results with an hetero aryl oxirane (entry 9).

To explain the observed (Z:E) selectivity, a closed transition state model, similar to the one proposed by Kishi, ${ }^{10 \mathrm{~b}}$ is shown in Scheme 3 . This model is supported by the observation that ortho substitution greatly enhances the (Z:E) selectivity.

In conclusion, a new simple one-pot three-component reaction protocol that involves tandem I-C/C-C bond formation has been developed for the synthesis of 3,4-difunctionalized homoallylic alcohols. Various substituted aryl oxiranes were utilized and good yields were obtained in all cases. This method is currently being extended to aliphatic and other 1,2disubstituted oxiranes in our laboratories. Considering the importance of homoallylic alcohols as versatile building blocks, the ester and iodo functionalities at 3 and 4 positions will become a new tools for the total synthesis of natural products.

\section{Supplementary Material}

Refer to Web version on PubMed Central for supplementary material.

\section{Acknowledgment}

We gratefully acknowledge the Robert A. Welch foundation (D-1361) and NIH (CA99995-1) for generous support of this work. We thank Mr. David W. Purkiss for assistance in NMR.

\section{References}

(1) (a). Smith AB III, Adams CM, Barbosa SAL, Degnan AP. J. Am. Chem. Soc 2003;125:350-351. [PubMed: 12517144] (b) Hornberger KR, Hamblet CL, Leighton JL. J. Am. Chem. Soc 2000;122:12894-12895.

(2) (a). Makita N, Hoshino Y, Yamamoto H. Angew. Chem. Int. Ed 2003;42:941-943. (b) Zhang WC, Li C-J. Tetrahedron 2000;56:2403-2411. (c) Wang L, Floreancig PE. Org. Lett 2004;6:569-572. [PubMed: 14961625] (d) Nicolaou KC, Kim DW, Baati R. Angew. Chem. Int. Ed 2002;41:37013704. (e) Liu B, Zhou W-S. Org. Lett 2004;6:71-74. [PubMed: 14703353] (f) Felpin FX, Lebreton J. J. Org. Chem 2002;67:9192-9199. [PubMed: 12492320]

(3). Kataoka K, Ode Y, Matsumoto M, Nokami J. Tetrahedron 2006;62:2471-2483.

(4). Lohse-Fraefel N, Carreira EM. Org. Lett 2005;7:2011-2014. [PubMed: 15876042]

(5) (a). Torres G, Torres W, Prieto JA. Tetrahedron 2004;60:10245-10251. (b) Okachi T, Murai N, Onaka M. Org. Lett 2003;5:85-87. [PubMed: 12509897]

(6). Duran F, Leman L, Ghini A, Burton G, Dauban P, Dodd RH. Org. Lett 2002;4:2481-2483. [PubMed: 12123356]

(7) (a). Yamamoto Y, Asao N. Chem. Rev 1993;93:2207-2293. (b) Denmark SE, Fu JP. Chem. Rev 2003;103:2763-2793. [PubMed: 12914480] 
(8) (a). Goldberg SD, Grubbs RH. Angew. Chem. Int. Ed 2002;41:807-810. (b) Williams DR, Brooks DA, Meyer KG, Clark MP. Tetrahedron Lett 1998;39:7251-7254. (c) Lombardo M, Morganti S, Trombini C. J. Org. Chem 2000;65:8767-8773. [PubMed: 11112602]

(9). Lee CHA, Loh TP. Tetrahedron Lett 2006;47:809-812.

(10) (a). Taniguchi M, Kobayashi S, Nakagawa M, Hino T, Kishi Y. Tetrahedron Lett 1986;27:47634766. (b) Taniguchi M, Hino T, Kishi Y. Tetrahedron Lett 1986;27:4767-4770.

(11). Zhang C, Lu X-Y. Synthesis 1996:586-588.

(12) (a). Li G, Wei H-X, Phelps BS, Purkiss DW, Kim SH. Org. Lett 2001;3:823-826. [PubMed: 11263891] (b) Wei H-X, Gao JJ, Li G, Pare PW. Tetrahedron Lett 2002;43:5677-5680. (c) Wei HX, Chen D, Xu X, Li G, Pare PW. Tetrahedron: Asymmetry 2003;14:971-974. (d) Wei H-X, Timmons C, Farag MA, Pare PW, Li G. Org. Biomol. Chem 2004;2:2893-2896. [PubMed: 15480451] (e) Wei H-X, Hu J, Jasoni RL, Li G, Pare PW. Helv. Chim. Acta 2004;87:2359-2363. (f) Chen D, Guo L, Kotti SRSS, Li G. Tetrahedron: Asymmetry 2005;16:1757-1762.(g) TimmonsCKattuboinaABanerjeeSLiGTetrahedron in press

(13). Borredon E, Delmas M, Gaset A. Tetrahedron Lett 1982;23:5283-5286.

Org Lett. Author manuscript; available in PMC 2009 January 5. 


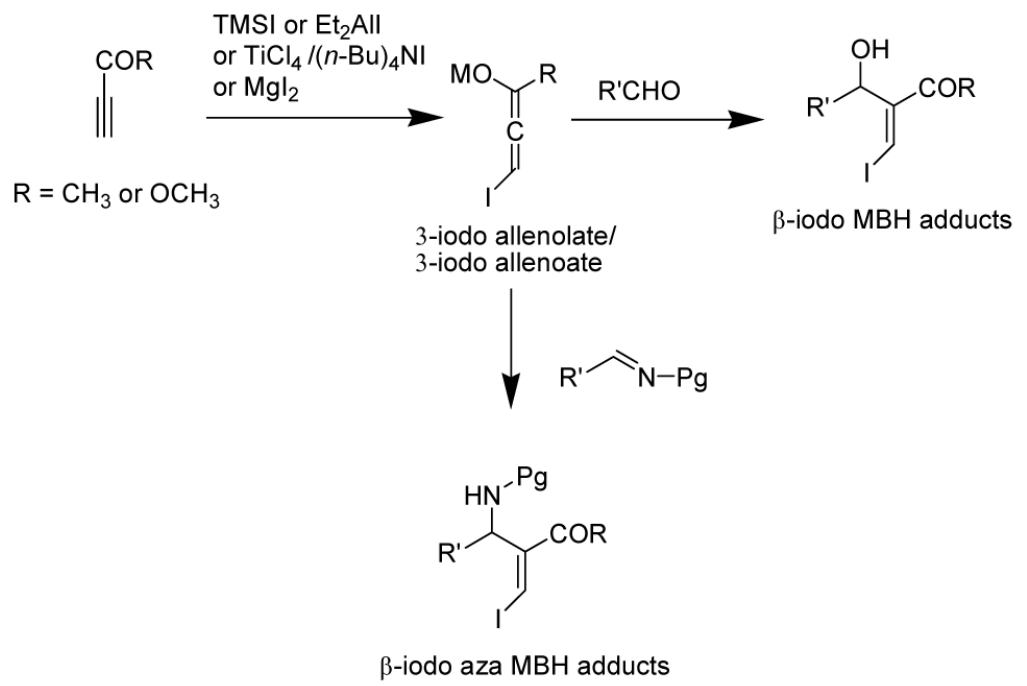

Scheme 1.

Org Lett. Author manuscript; available in PMC 2009 January 5. 


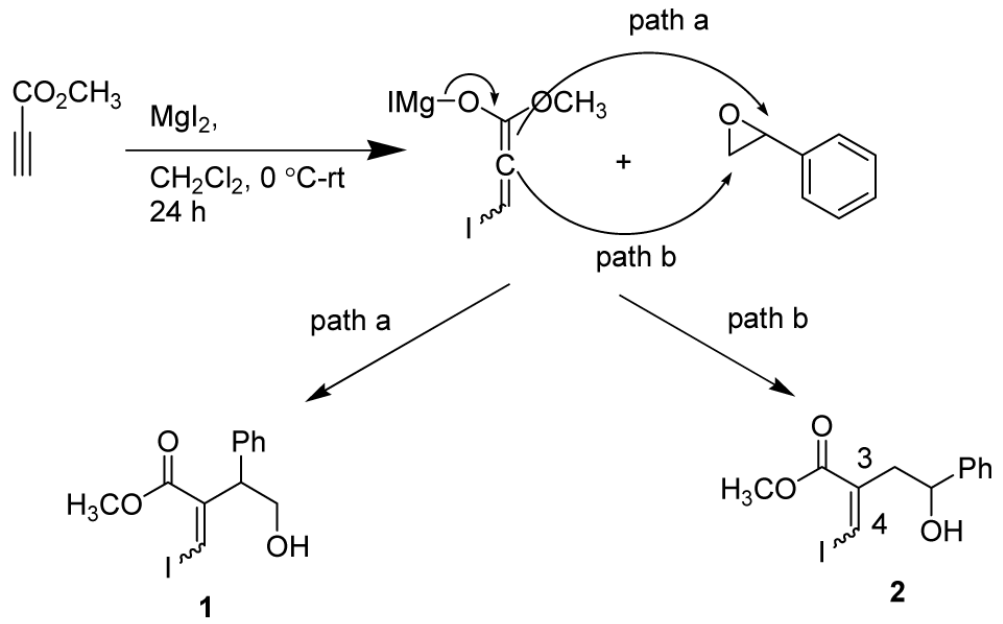

Scheme 2.

Org Lett. Author manuscript; available in PMC 2009 January 5. 


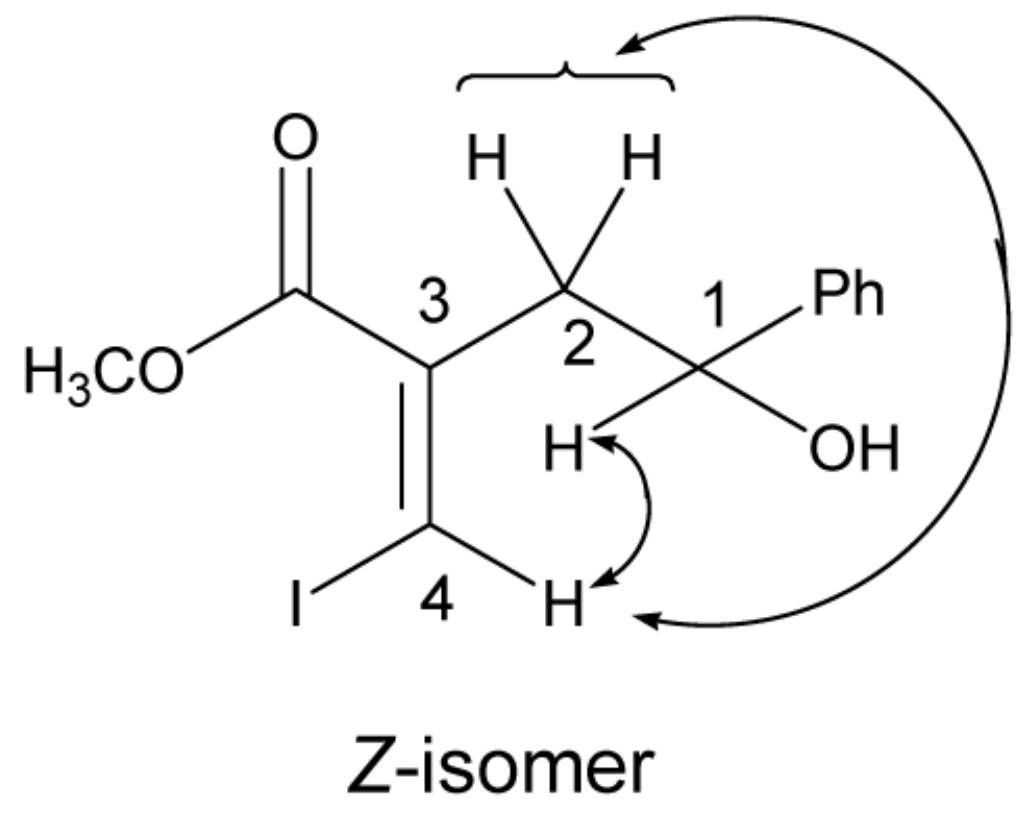

Figure 1.

NOE correlations in (Z)-2 

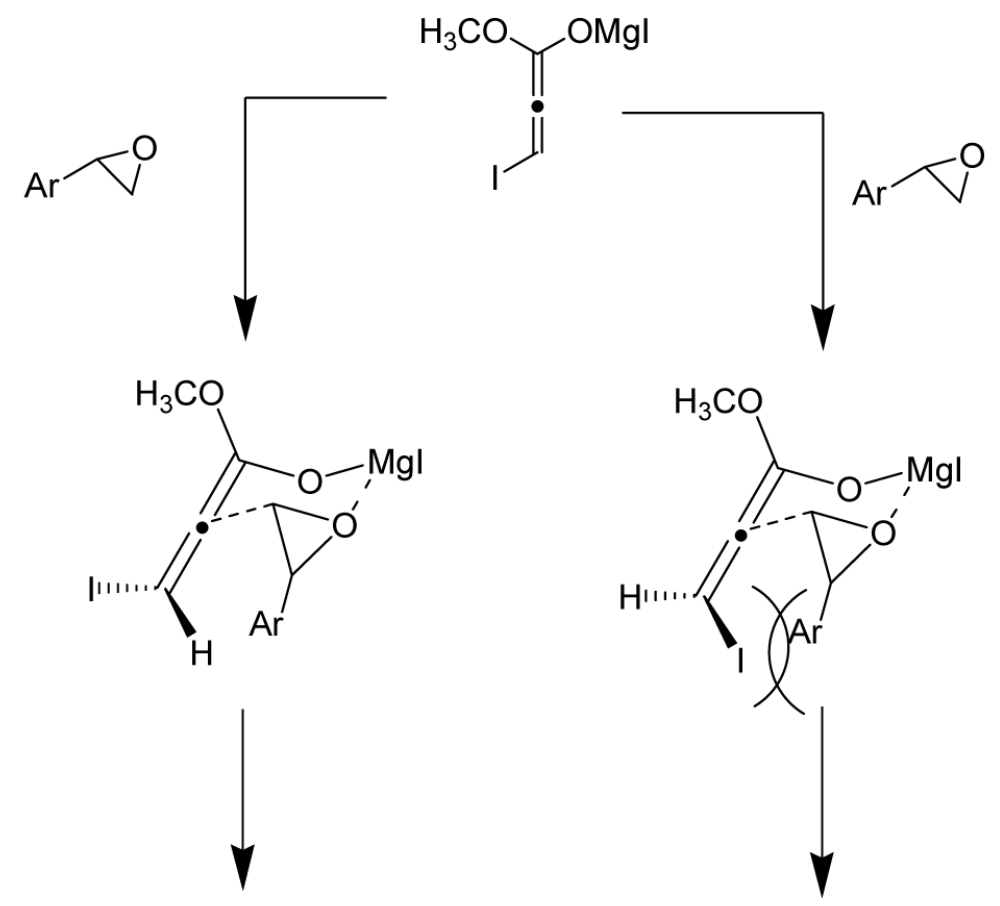<smiles>COC(=O)/C(=C\I)CC(O)Br</smiles>

— Z-isomer (major)<smiles>COC(=O)/C(=C/I)CC(O)[Al]</smiles>

E-isomer (minor)

Scheme 3.

Proposed transition state model 


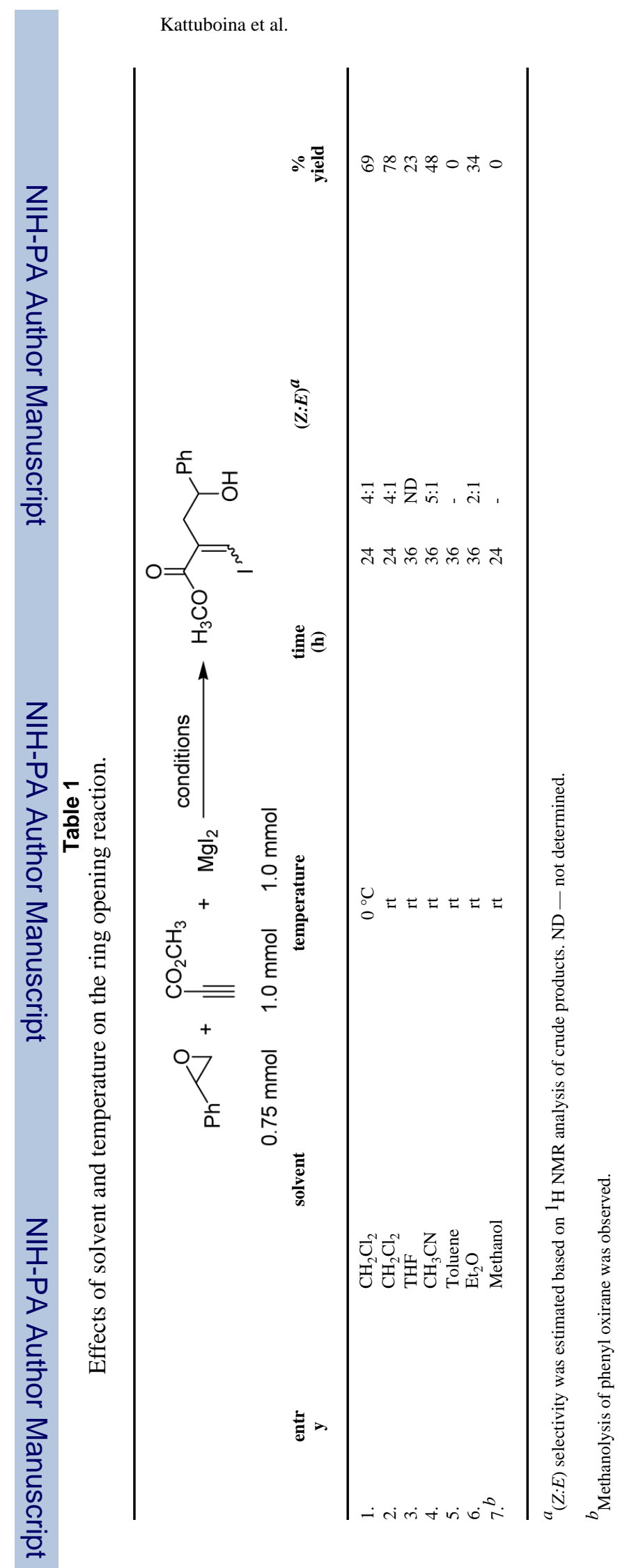

Page 9 
Table 2

Results of ring opening of aryl oxiranes with 3-iodo allenoates.

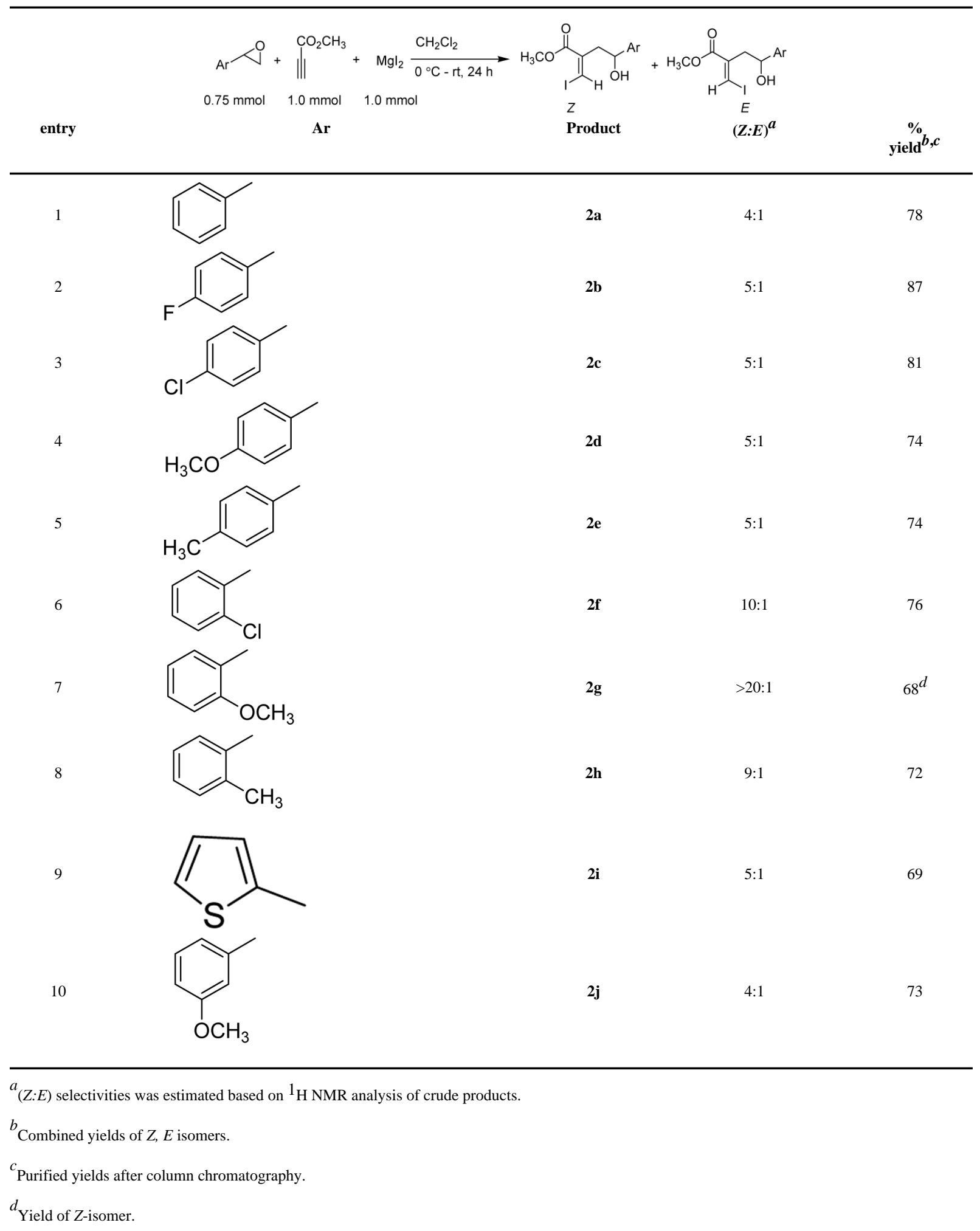

Org Lett. Author manuscript; available in PMC 2009 January 5. 